\title{
The Construction and Management System of Eco-clean Small Water- shed in the Subtropical Zone
}

\author{
Luo Jia ${ }^{1}$, Chen Jianhua ${ }^{* 1}$, Luo $\mathrm{Jia}^{2}$, Zhou Xiaoling ${ }^{2}$,Tian Yuxin ${ }^{2}$,Zhang Can- \\ ming $^{2}$,Li Xiquan ${ }^{2}$
}

${ }^{1}$ Central South University of Forestry and Technology,Changsha,Hunan,China

${ }^{2}$ Hunan Academy of Forestry, Changsha, Hunan, China

Keywords: Construction; Eco-management; Small Eco-clean Watershed; Subtropical Zone.

\begin{abstract}
This study aimed to investigate the construction and management system of eco-clean Nver-Zhai small watershed to solve the existing eco-environment problems. The study area was divided into three protection zones which include ecological restoration of conservation area, ecological control area and wetland protection area. These three protection zones were treated in several selected protection ways and monitored at the Ecological Station of Cili County to assess the ecological benefit of these treatments. Finally, based on the results, the construction and management system of Nver-Zhai were built.
\end{abstract}

\section{INSTRUCTION}

As be the smallest unit of water collection, a small watershed is the radical departure for water source protection. Only when small watersheds are well managed and protected, can the ecological system be protected, also the quality of water into reservoirs and rivers be basically guaranteed [1]. Establishing small eco-clean watershed, which unit was set based on a valley and follows the laws of ecology and nature without affecting the landscape, is a way to construct and manage the water resource comprehensively.Via this method,the rational use and optimization of resources in a valley can be realized, the harmony between human beings and nature can be kept and the sustainable development of economic social [2] and circulative eco-system can be built. Since 2003, the research on small eco-clean watersheds has began all over China and got some progress in Beijing city and Shandong province and other places[3-11]. However, few researches has been carried out in south part of China. This paper reported the establishing process of Nver-Zhai eco-clean small watersheds based on the topographic feature of Nver-Zhai watershed and integration of mountain, water, forest, cropland and road. This process was monitored at the Ecology Localization Research and Experiment Station of Cili County and the monitoring results were used to analyze the mechanism and comprehensive effect of the process of restoration and reconstruction of vegetation in subtropical forest ecosystem.

The study area, Nver-Zhai small watershed, is located in the hinderland of Wuling Mountain in the middle of Yangtze River $\left(111^{\circ} 14^{\prime} 27.68^{\prime \prime} \mathrm{E} 、 29^{\circ} 24^{\prime} 04.61^{\prime \prime} \mathrm{N}\right)$ and is approximately $7 \mathrm{~km}$ away from the northwest of Cili County. It is the second grade tributary of Lishui River and approximately in a north-south direction. The altitude of the outlet is $210 \mathrm{~m}$. The highest peak is $917.4 \mathrm{~m}$ and the length of the main gully is about $1.2 \mathrm{~km}$. The total area of the small watershed is $3.15 \mathrm{~km}^{2}$ with the population of 277 . This area is a typical subtropical humid zone with adequate rainfall. The average annual rainfall is about $1400 \mathrm{~mm}$ and the rainfall from April to August takes up more than $60 \%$ of the annual rainfall. The altitude of the watershed ranges from $210.0 \mathrm{~m}$ to $917.4 \mathrm{~m}$. The parent rocks are consisted of shale and sandstone and the soil is mainly rea soil, mountain yellow soil and yellow-brown soil. The terrain of small watershed is complicated. The density of gully is about $2.6 \mathrm{~km} / \mathrm{km}^{2}$ and the vertical gradient of the main gully is about $28.4 \%$. In the watershed there exist paddy field $4.13 \mathrm{hm}^{2}$,vegetable field $1.54 \mathrm{hm}^{2}$, dry land $5.07 \mathrm{hm}^{2}$, woodland $202.32 \mathrm{hm}^{2}$, water area $38.80 \mathrm{hm}^{2}$, house site $4.62 \mathrm{hm}^{2}$, road $24.52 \mathrm{hm}^{2}$, the land use status quo to see in Figure.1. 


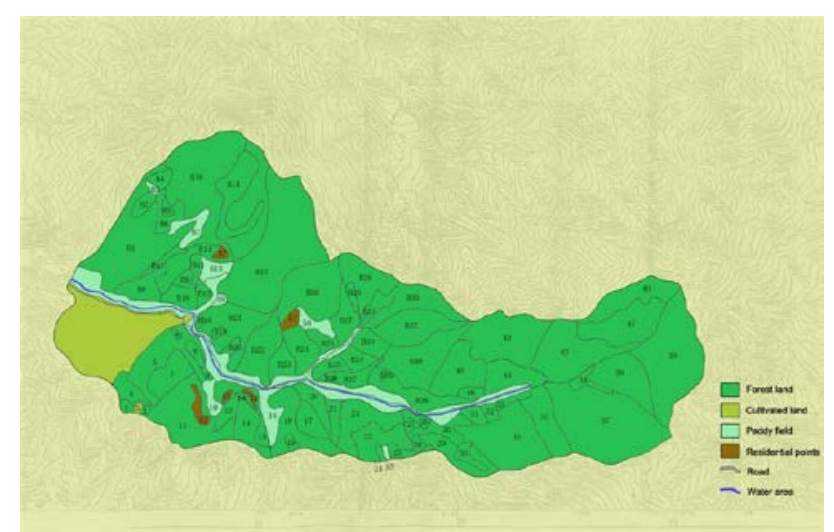

Figure 1. Current land use map of Nver-Zhai small watershed

\section{CONSTRUCTION AND MANAGEMENT SYSTEM OF SMALL WATERLAND}

\subsection{Construction Method}

According to practice results of the construction of small eco-clean watersheds in recent years and Soil and Water Conservation Planning, the steps of construction of small eco-clean watershed in Nver-Zhai are designed and summarized as follows:

(1) A research was made to collect and monitor the existing basic information of this small watershed, including the conditions of the mountain slope, gully, non-point source pollution, road, surroundings of the county in the watershed. At the same time, the assessment of economic, social and ecological benefits within this watershed was made.

(2) Objectives of establishing eco-clean small watershed was identified based on the ecological functional positioning and basic standard of small eco-clean watershed.

(3) The guideline and basic principles of constructing small eco-clean watershed were identified.

(4) Different functional areas of constructing eco-clean small watershed were divided.

(5) Compiling related text, and provide the reference for the construction of small eco-clean watershed system in South China.

\subsection{Management Method}

(1) Follow and investigate the executive condition of establishing small eco-clean watershed in Nver-Zhai.

(2) Via the long-term located monitoring, evaluate the small watershed comprehensive harness benefit in Nver-Zhai.

\section{RESULTS AND ANALYSIS}

\subsection{Problem Analysis}

(1)Slope and mountain massif: Since the soil is thin, the slopes are steep and anti-erosion ability of soil is poor, in the rainy season, when the grades of the slopes are large and the surface run-off increased, to some extent, there will happen water and soil loss. According to the relative research[12], in the largest rainfall of $148 \mathrm{~mm}$ for the past few years, the rainfall eroding force reached 2027.52 MJ $\mathrm{mm} /\left(\mathrm{hm}^{2} \cdot \mathrm{h}\right)$, the sediment yield modulus achieved $448.37 \mathrm{t} / \mathrm{km}^{2}$ and the runoff depth attained $60.19 \mathrm{~mm}$. All the data are the highest in the observed data, and are directly relative to the prolonged and intensive rainfall. Because the large rainfall erosion force caused big effect on topsoil splash erosion and rill erosion, the overland runoff possessed large capacity, sequentially, happened the larger loss of sediment and influenced the slopes and mountain massif.

(2) Gully: Ditch bank erosion, ditch cut, the ravine stream directly flow. At the confluence of gullies, the wallop of water current is large, the runoff potentially wash out the banks of river and gully and erode the gully road. 
(3) Agricultural non-point source pollution: There exist the non-point source pollution, such as crop-dusting, livestock pollution, industry wound and inorganic fertilizer, in the small watershed. Monitor indicates that overland runoff is significantly relevant to average rainfall intensity and total nitrogen content in the rainfall. And in the slope runoff area with good vegetation, the relativity of the total content of nutrient elements, such as phosphorus and nitrogen, and average rainfall intensity is large. Forestry production will increase the loss of nutrient elements, water and soil, especially the loss of sediment. This shows there exists forestry non-point source pollution. The highest content of nitrogen in headwaters, which only has vegetation and little human activity, could reach $1.5001 \pm 0.483 \mathrm{mg} \cdot \mathrm{L}^{-1}$. Impacted by non-point source pollution, the content of nitrogen is $0.8289 \pm 0.372 \mathrm{mg} \cdot \mathrm{L}^{-1}$ in the total outlet. The outlet takes up water in different qualities, after removed, diffused and diluted by the river, there still has high content of pollutant and directly influence the water quality in downstream. The total content of phosphorus is $0.0226 \pm 0.027 \mathrm{mg} \cdot \mathrm{L}^{-1}$, and the total content of phosphorus in the outlet is the largest, it reaches $0.0306 \pm 0.028 \mathrm{mg} \cdot \mathrm{L}^{-1}$. It indicates that phosphorus has poor ability to diffuse and remove through the river, moreover, it has concentration. The permanganate index and ammonia nitrogen content in outlet are all higher than headstream. In the area where has heavy population and concentration of production and living, the agricultural non-point source pollution and rural waste and sewage pollution is most serious.

(4)Road: Poor drainage, coast, sludge road. Due to the damage of vegetation on slope, the water loss and soil erosion was exacerbated. Once heavy rainfall happens, the slope runoff will carry a large amount of silt to the road. That will make the road become muddy and cause incommodiousness to passerby.

(5)Surroundings of the village: The obvious environment problems of the village are severe pollution of gutter way, collapse of houses, disorder in unused spaces and backwardness of road conditions.

\subsection{Establishment of small eco-clean watershed in Nver-Zhai}

Based on the comprehensive purpose of "ecological security, environment cleaning, scenery elegant, humane harmony, management orderliness”, the establishment of small eco-clean watershed in Nver-Zhai accomplished "people foremost, harmony between man and nature”. Close to the protection of water resource, divided the small watershed that require governance into ecological restoration of conservation area, ecological control area and wetland protection area (see Figure.2).Comprehensively applied governance measures to realize eco-environment construction and the protection of water and soil resource.

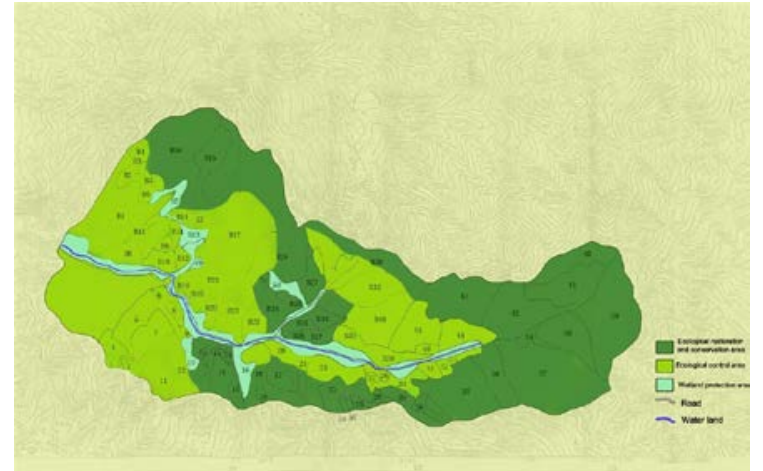

Figure 2. Construction subarea graphs of Nver-Zhai small eco-clean watershed

Ecological restoration of conservation area

This area located between the mountaintop and top of the hillside, the gradient is more than $25^{\circ}$,and there is little human activity, no artificial interference such as exploitation, construction and large-scale agriculture. The proportion of the area is about $1.60 \mathrm{~km}^{2}$

The control method of introducing broad-leaved trees to pure forest: Aiming at solving the problems of single structures in pure Cunninghamia lanceolata and Pinus massoniana forest, fertility attenuation, decrease of biomass and poor stability of the forests, applying artificial assistant measures to control the transmittance of the forest. Emphatically introducing and cultivating shade- 
tolerant broad-leaved trees, and foster mixed forest, such as Pinus massoniana- Quercus palustris mixed forest, Pinus massoniana - Liquidambar formosana mixed forest, Pinus massoniana - Cyclobalanopsis glauca mixed forest, Cunninghamia lanceolata - Phoebe zhennan mixed forest, Cunninghamia lanceolata -Betula luminifera mixed forest. Improve the ability of eco-service function and disaster-resistance of the forests, and significantly increase the biodiversity.

The management of sub-natural forest: Although pure forest has good short-term economic benefits, it has the problems of poor structure, fertility decline, low biomass and poor eco-benefit. The implement of sub-nature management could influence the environment of forests and shows up on the respect of soil fertility status, biodiversity, community structures and forest productivity. Starting from the area of the ability of soil seed banks, and implement the process of sub-natural forest ecological response and renewal development.

Aiming at the different managements of Cunninghamia lanceolata and Pinus massoniana, applying the method of located observation and investigation to study on the maintenance of ecoresponse and ability of renovation in every forest under different managements, and construct the model of maintenance of renewal capacity.

i) The eco-response of sub-natural forest

Via the monitor of the respective of soil seed banks, transparency, biodiversity, community structure, capacity of soil and water, reflect the process of eco-response in every forest under different management.

ii) The maintenance of the renewal ability in sun-natural forest

Based on the capacity of soil seed bank, study on the relationship of biodiversity, the capacity of soil seed bank and transparency, establish a ternary mathematical model of the three factors and form the pivotal technology of maintaining the renewal ability in sub-natural forest management.

The hill-closure reforestation measure

For the pure forest where the gradient is more than $35^{\circ}$, implement the measures of hill-side closure grazing prohibition and set guardrails to decrease the artificial disturbs. Protect understory shrub, herbage and litter, to improve the benefit of water and soil conservation in forest. Close the forest which has bush wood, sparse wood or scattered trees, with the aid of regeneration or natural seeding to cultivate the forest. Take banned in the sparsely populated high mountains and distant hills.

Ecological control area

Selection (Heading This area is located between the lower slope and basal slope, the gradient is no more than $25^{\circ}$, the mainly soil erosion is gully erosion and surface erosion. This area mostly includes frequent human activities area and agricultural area. The proportion of the area is about 1.35 $\mathrm{km}^{2}$. Aiming at solve the problems of heavy population, soil and water loss, concentration of production and living and severe pollution of agricultural non-point source and rural waste and sewage, major harness the areas of village, sloping cropland, fruit forest and pure forest.

Village cleaning method: Implement the rural cleaning project, focus on "two minus and one control" of agricultural chemical and the disposal of fertilizer, domestic swage and garbage. Guide farmers to proceed scientific and balanced fertilization, clear the production specification, no sparing of pesticides within the two weeks before the agricultural products listed. Stop burning crop straw insitu, forbid optionally piling up the toxic and deleterious matters on the field, waste landfill must meet the standards.

Vegetation restoration measures in steep slope cultivated land

Treating slope cultivated land with different vegetation restoration measures, such Cinnamomum camphora + Liquidambar formosana, Cinnamomum camphora + Cupressus funebris, Citrus reticulata + Arachishypogaea, Cunninghamia lanceolata + Liquidambar formosana, Pinus massoniana + Cinnamomum camphora, Pinus massoniana+ Bischofia polycarpa, Liquidambar formosana + Cunninghamia lanceolata, Cunninghamia lanceolata + Cupressus funebris + Pinus massoniana, Phyllostachys pubescens + Alnus cremastogyne + Cunninghamia lanceolata + Koelreuteria paniculata, Phyllostachys pubescens + Alnus cremastogyne + Cunninghamia lanceolata + Castanea mollissima 
and tangerine, to decrease overland runoff and sediment production in the slope cultivated land. Afforest after sloping fields reforms can better reduce the overland runoff and sediment production than direct afforestation.

Optimal allocation of economic and fruit tree forest:

i) Economic forest: For pure Eucommia ulmoides forest, mix with conifer species (such as Cunninghamia lanceolata). Mix pure Vernicia fordii forest in group with Cunninghamia lanceolata and Liquidambar formosana to adjust the structure of tree species and improve the quality of forest.

ii) Fruit tree forest: For the fruit tree forest land in the small watershed, aim at solve the problems of scarce understory and unitary structure of understory in the pure Citrus reticulate forest, apply the technology of soft- ridge optimization. This method is simple, ordered and less land occupied. And it helps cultivation and makes Citrus reticulata develop healthy root system, and return a larger increasing production. Along the contour manual build one-meter-wide soft-ridge in every $20 \mathrm{~m}$, densely cultivate honeysuckle on the soft-ridge in a ribbon pattern. It could prevent overland runoff and sediment; as a consequence, the overland runoff will soak into the soil and reduce the loss of water and soil.

Road maintenance measure: For the phenomenon of road landslide, apply the ecological slope protection measures such as grass plantation, plant cultivation on the alien earth, liquid spraying seed plant, tiling turf, bio-bag revetment and ecological gridding slop protection. Aiming at solve the problem of sludge road, clean the barriers and garbage on the road timely, and keep road clear for traffic. Aiming at solve the problem of poor road drainage, take the measure of building ecological drainage ditch, adopt vegetation measures or combine vegetation measure with engineering measure.

Eetland protection area

This area located in downstream of Nver-Zhai small watershed and the two sided of it, which include water area and riverside region, such as flood land and rivers, and primarily be paddy field. The proportion is about $0.21 \mathrm{~km}^{2}$.

Gully sorting measure:Clean the garbage centralized and sediment accumulated gully, reasonably clear obstacles. Based on the different composite structure, set vegetation along the gully road, and build vegetated buffer strips, as far as possible to protect longshore tree-shrubs and aquatic plant.

Dam protection measure: On the two sides of the gully, build guard dam to control flood and store water. Improve the dam erosion reference and prevent the loss of water and soil.

Safeguard measure of farmland:This measure mainly aims at paddy field. As for solve the nonpoint source pollution in farmland, apply the method of reduce or control the application amount of pesticide and fertilizer. Monitor the origin, trait and change of non-point source pollution; control the discharge amount of garbage and pollutant in the lowest limit. Set forest or grass filter strips between the water and farmland to reduce the content of nitrogen and phosphorus in the water. At the same time, utilize complementarity of different crops on nutrient absorption; take rational intercropping to significantly nutrient elements loss and water pollution.

Auth The strategy for Nver-Zhai small eco-clean watershed management

The strategy for Nver-Zhai small eco-clean watershed management

Since 1999, the ecological monitoring station was set up on the farmland returning to forest in Cili County, Hunan Province. The station possesses 1 mini weather station, 1 flow-measuring weir in both primary and secondary outlet, 30 slope runoff plots. It also owns positioning monitoring equipments including soil moisture detector TDR, soil carbon flux detector, forest transpiration detector TDP, canopy closure device and stem flow device. Since the monitoring station set up for 15 years, obtained more than 100,000 monitoring data, carried out the prolonged located monitor of microclimate (include rainfall, evaporation, air temperature, ground temperature, wind speed, wind direction ) in small watershed, the soil and water loss on slopping land in the area of Pinus massoniana, Eucommia ulmoides, Machilus pingii, Citrus reticulata, Vernicia fordii, closed hills for natural succession, Cinnamomum camphora + Liquidambar formosana, Cinnamomum camphora + Cupressus funebris, Phyllostachys pubescens and relevant control area. Also, the monitoring about 
forest precipitation, stem flow, transpiration, soil moisture content in the Eucommia ulmoides forest, the runoff and sediment in the primary and secondary hydrological station of total outlet was executed. Via the long-term located monitoring, evaluate the comprehensive harnessing effects of Nver-Zhai small watershed.

Set up the early warning mechanism. Monitor the water quality of the small watershed regularly; establish an assessment index system about the enrichment of eutrophication in small eco-clean watershed. If the index of total amount of nitrogen, phosphorus, ammonia nitrogen and permanganate salt was exceeding, the control measures will be took. Quantitatively monitor the loss of water and soil in small watershed, once the index overrun $500 \mathrm{t} / \mathrm{km}^{2} \cdot \mathrm{a}$, take the measures of slope protection and gully regulation, establish the ecological management strategy of small Nver-Zhai eco-clean watershed.

\section{DISCUSSION}

The establishment of small eco-clean watershed is a type of emerging ecological management pattern which based on the past comprehensive harnessing of small watershed. Directed by the idea of "the construction of harmonious society" and "the construction of new socialist countryside", take sustainable development of the ecological environment and sustainable utilization of water and soil resource as fundamental objectives; Focus on human being, coordinate with the need of local farmers' economical development to construct and manage the small eco-clean watershed in NverZhai. Aim at the problems emerged in the construction of Nver-Zhai small eco-clean watershed, deeply consider and discuss how to carry out the construction and ecological management of small eco-clean watershed from the macro, meso and micro perspectives.

Table.1 Comprehensive measures of construction of small eco-clean watershed in Nver-Zhai

\begin{tabular}{|c|c|c|c|}
\hline \multirow{2}{*}{\multicolumn{2}{|c|}{ No. and name }} & \multicolumn{2}{|l|}{ Scale } \\
\hline & & Amount & Location \\
\hline \multicolumn{2}{|l|}{ Total area $/ \mathrm{km}^{2}$} & 3.15 & \\
\hline \multicolumn{2}{|c|}{$\begin{array}{l}\text { The area of ecological restoration and conservation } \\
\text { are } / \mathrm{km}^{2}\end{array}$} & 1.60 & \\
\hline \multicolumn{2}{|c|}{ The area of ecological control area $/ \mathrm{km}^{2}$} & 1.35 & \\
\hline \multicolumn{2}{|c|}{ The area of wetland protection area $/ \mathrm{km}^{2}$} & 0.21 & \\
\hline \multirow{3}{*}{$\begin{array}{l}\text { Ecological restora- } \\
\text { tion and conserva- } \\
\text { tion area }\end{array}$} & $\begin{array}{l}\text { The control method of introducing } \\
\text { broad-leaved trees to pure forest }\end{array}$ & & $\begin{array}{l}\text { Pinus massoniana and Cun- } \\
\text { ninghamia lanceolata area } \\
\text { at the external area of the } \\
\text { small watershed. }\end{array}$ \\
\hline & $\begin{array}{l}\text { The management of sub-natural for- } \\
\text { est }\end{array}$ & & Pure forest area \\
\hline & $\begin{array}{l}\text { The hill-closure reforestation meas- } \\
\text { ure }\end{array}$ & & Pure broad-leaved forest \\
\hline \multirow{4}{*}{$\begin{array}{l}\text { Ecological control } \\
\text { area }\end{array}$} & Village cleaning method & & Residential area \\
\hline & $\begin{array}{l}\text { Vegetation restoration measures in } \\
\text { steep slope cultivated land }\end{array}$ & & Sloping field area \\
\hline & $\begin{array}{l}\text { Optimal allocation of economic and } \\
\text { fruit tree forest }\end{array}$ & & $\begin{array}{l}\text { Economic and fruit tree for- } \\
\text { est of Eucommia ulmoides } \\
\text { and Citrus reticulate }\end{array}$ \\
\hline & Road maintenance measure & & Road area \\
\hline \multirow{3}{*}{$\begin{array}{l}\text { Wetland protec- } \\
\text { tion area }\end{array}$} & Gully sorting measure & & Gully road \\
\hline & Dam protection measure & & Sides of the gully \\
\hline & Safeguard measure of farmland & & Paddy field \\
\hline
\end{tabular}

\section{ACKNOWLEDGMENTS}


This research is supported by Research and Demonstration of Yangtze River Conservation Forest Quality Control and Efficient Management Technology of China under Grant No.2015BAD07B04, Experiment and Demonstration of Close-to-nature Forest Management program of Hunan Province under Grant No.2012-HNLYKY-01 and the Youth Scientific Research Innovation Fund Project of Hunan Academy of Forestry No.2013LQJ11. *means corresponding author. Corresponding Author: Chen Jianhua(1955-), Male,Professor, Dcotoral supervisor. Mainly engaged in silviculture teaching and scientific research work.

\section{REFERENCES}

[1]Liu Dagen, Yao Yuzhong, Li Shirong , Construction and management of small eco-clean watershed in Beijing [J].Soil and Water Conservation,2008,(8):15-17.

[2]Bi Xiaogang, Yang Jinhuai, Li Yonggui, The thought and practice of constructing small ecoclean watershed in Beijing [J]. Science of Soil and Water Conservation,2005(1):18-20.

[3]Yang Jinhuai, Wu JIngdong, Qi Shenglin, Research of the construction technical measures of small eco-clean watershed in Beijing [J]. Science of Soil and Water Conservation,2007,5(4):1821.

[4]Yang Kun, Research of the governance model of small eco-clean watershed in Beijing [J]. Soil and Water Conservation, 2009(4):4 - 6.

[5]Hu Zongming, The practice and thought of constructing small eco-clean watershed in Changping District [J]. Soil and Water Conservation,2007(9):45-47.

[6]Zheng Cuiling, The exploration and practice of constructing small eco-clean watershed in Mentougou District [J]. Soil and Water Conservation,2007(9):34-36.

[7]Zhang Jing, Zhang Daiming, Wang Yaping, The research on water-soil conservation measures of small eco-clean watershed in Qingdao City [J]. Soil and Water Conservation,2010(3):21-23.

[8]Song Zhengtai, The practice of construction small eco-clean watershed in Dashangou[J].Soil and Water Conservation,2009(8):57-58.

[9]Liu Dagen, Lan Haijun, Hu Zongming, The practice and exploration of constructing small ecoclean watershed in Xiangtan [J].Soil and Water Conservation,2007(9):27-28

[10] Ding Yonghua, Chi Zhitao, The exploration and analysis about the construction model of small eco-clean watershed in Taihe District, Qingdao[J]. Shandong Water Resource,2008(4):27-28.

[11] Huang Zhongliang,Zhou Xiaoling,Chang Mingqing,Wang Ping, Evaluate the surface water environment of Nuer-village forest watershed in Wuling Mountain area [J].Hunan Forestry Science \& Technology,2011,38(5):22-26.

[12]Zhou Jing, Zhang Xudong, He Dan, Zhou Jinxing, Zhou Xiaoling, Wang Zhongjian, The characteristics of runoff and sediment in Nver-Zhai small watershed in Wuling Moutain [J],Science of Soil and Water Conservation,2011,9(1):33-38. 